\title{
DÜBLIN
}

Technological University Dublin

ARROW@TU Dublin

\section{A Comparative Analysis of Pretreatment Strategies on the Properties and Hydrolysis of Brewers' Spent Grain}

\author{
Rajeev Ravindran \\ Technological University Dublin \\ Swarna Jaiswal \\ Technological University Dublin, swarna.jaiswal@tudublin.ie \\ Nissreen Abu-Ghannam \\ Technological University Dublin, nissreen.abughannam@tudublin.ie
}

See next page for additional authors

Follow this and additional works at: https://arrow.tudublin.ie/schfsehart

Part of the Bioresource and Agricultural Engineering Commons

\section{Recommended Citation}

Ravindran, R., Jaiswal, S., Abu-ghannam, N. \& Jaiswal, A. K. (2017). A comparative analysis of pretreatment strategies on the properties and hydrolysis of Brewers' spent grain. Bioresource Technology, June 2017 doi:10.1016/j.biortech.2017.06.039

This Article is brought to you for free and open access by the School of Food Science and Environmental Health at ARROW@TU Dublin. It has been accepted for inclusion in Articles by an authorized administrator of ARROW@TU Dublin. For more information, please contact arrow.admin@tudublin.ie, aisling.coyne@tudublin.ie, gerard.connolly@tudublin.ie.

Funder: Technological University Dublin (DIT), Dublin, Ireland

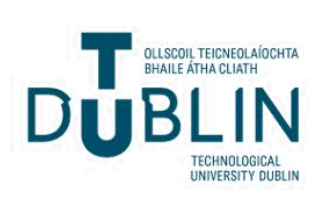




\section{Authors}

Rajeev Ravindran, Swarna Jaiswal, Nissreen Abu-Ghannam, and Amit Jaiswal

This article is available at ARROW@TU Dublin: https://arrow.tudublin.ie/schfsehart/238 


\section{Accepted Manuscript}

A comparative analysis of pretreatment strategies on the properties and hydrolysis of Brewers' spent grain

Rajeev Ravindran, Swarna Jaiswal, Nissreen Abu-Ghannam, Amit K. Jaiswal

PII:

$$
\text { S0960-8524(17)30926-4 }
$$

DOI:

$$
\text { http://dx.doi.org/10.1016/j.biortech.2017.06.039 }
$$

Reference:

$$
\text { BITE } 18276
$$

To appear in:

$$
\text { Bioresource Technology }
$$

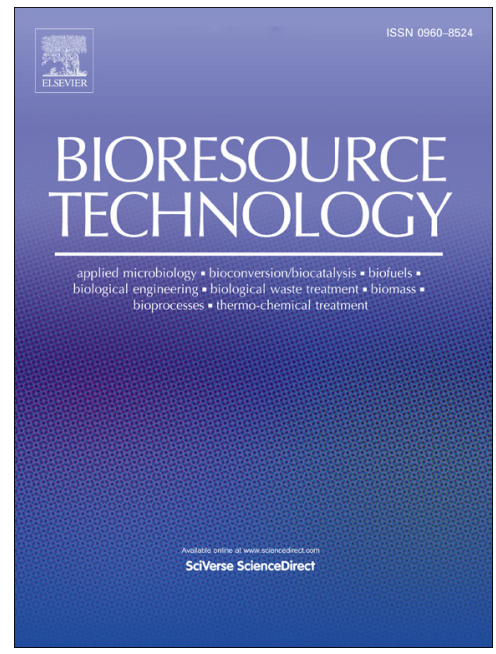

Received Date: $\quad 30$ April 2017

Revised Date: 6 June 2017

Accepted Date: $\quad 7$ June 2017

Please cite this article as: Ravindran, R., Jaiswal, S., Abu-Ghannam, N., Jaiswal, A.K., A comparative analysis of pretreatment strategies on the properties and hydrolysis of Brewers' spent grain, Bioresource Technology (2017), doi: http://dx.doi.org/10.1016/j.biortech.2017.06.039

This is a PDF file of an unedited manuscript that has been accepted for publication. As a service to our customers we are providing this early version of the manuscript. The manuscript will undergo copyediting, typesetting, and review of the resulting proof before it is published in its final form. Please note that during the production process errors may be discovered which could affect the content, and all legal disclaimers that apply to the journal pertain. 
A comparative analysis of pretreatment strategies on the properties and hydrolysis of Brewers' spent grain

Rajeev Ravindran ${ }^{1}$, Swarna Jaiswal ${ }^{2}$, Nissreen Abu-Ghannam ${ }^{1}$, Amit K. Jaiswal ${ }^{1}$ *

${ }^{1}$ School of Food Science and Environmental Health, College of Sciences and Health, Dublin Institute of Technology, Cathal Brugha Street, Dublin 1, Republic of Ireland.

${ }^{2}$ Centre for Research in Engineering and Surface Technology, FOCAS Institute, Dublin Institute of Technology, Kevin Street, Dublin 8, Republic of Ireland.

*Corresponding author:

Email: amit.jaiswal@dit.ie; akjaiswal@outlook.com

Tel: +35314024547 


\begin{abstract}
In this study, brewer's spent grain (BSG) was subjected to a range pretreatments to study the effect on reducing sugar yield. Glucose and xylose were found to be the predominant sugars in BSG. Brewers spent grain was high in cellulose $(19.21 \mathrm{~g} / 100 \mathrm{~g}$ of BSG) and lignin content (30.84g/100g of BSG). Microwave assisted alkali (MAA) pretreatment was found to be the most effective pretreatment for BSG, where the pretreatment was conducted at $400 \mathrm{~W}$ for $60 \mathrm{~s}$. A maximum reducing yield was observed with high biomass loading $(1 \mathrm{~g} / 10 \mathrm{ml})$, cellulase $(158.76$ $\mu 1 / 10 \mathrm{ml})$, hemicellulase $(153.3 \mu \mathrm{l} / 10 \mathrm{ml}), \mathrm{pH}(5.4)$ and an incubation time (120h). Upon enzymatic hydrolysis, MAA pretreated BSG yielded $228.25 \mathrm{mg}$ of reducing sugar/g of BSG which was 2.86-fold higher compared to native BSG (79.67 mg/g of BSG); simultaneously BSG was de-lignified significantly. The changes in functional groups, crystallinity and thermal behaviour was studies by means of FTIR, XRD and DSC, respectively.
\end{abstract}

Keywords: Lignocellulose; biomass pretreatment; Brewer's spent grain; reducing sugar; microwave assisted alkali pretreatment; 


\section{Introduction}

Brewer's spent grain is a by-product of the brewing industry. It is obtained from barley and is essentially the outer pericarp seed coat layer of the malted barley grain that remains after the mashing process (Mussatto et al., 2006). It is structurally heterogeneous in nature and consists of husk, pericarp and fractions of endosperm (Forssell et al., 2008). Almost 30\% of the starting malted grain end up as BSG by the end of the brewing process. Every hectolitre of beer generates 15-20 kg of BSG which corresponds to 34 million tonnes of wet BSG generated annually worldwide (Xiros \& Christakopoulos, 2012). Although rich in polysaccharides, proteins and lignin, which can be used for industrial exploitation, BSG is generally used as animal feed. 'The New Waste Framework Directive' was introduced by the EU in 2008/09 as a new approach to curb food waste such as BSG and as well as new processes for reuse and recycling (Ravindran \& Jaiswal, 2016a). BSG is mainly composed of cellulose, hemicellulose and lignin along with considerable amounts of proteins and lipids. The chemical composition of BSG along with its high fibre content enables it to act as a potential feedstock for several commercial processes with applications in biotechnology, thermochemical and biochemical engineering such as renewable energy, substrate cultivation, enzyme production, bread making, ethanol, butanol and xylitol, activated carbon, charcoal, lignin and oligo saccharides (Ferraz et al., 2013; Ravindran \& Jaiswal, 2016c).

As mentioned above, BSG is lignocellulosic in nature and is mainly composed of polysaccharides, lignin, lipids and a small fraction of proteins. The polysaccharides in BSG are represented by cellulose (formed by repeating units of $\beta$-D-glucopyranose) and hemicellulose (heteropolymer formed by non-cellulose sugars such as mannose, xylose, galactose and 
arabinose) and comprise almost $45 \%$ of total dry weight. Lignin, a highly branched phenyl propane polymer, forms the rest of the BSG composition (Mussatto et al., 2006). The effective utilisation of BSG for valorisation requires techniques to disrupt the naturally ordered structure and remove lignin. Pretreatments are essential strategies that can achieve this aim and facilitate the exposure of the polysaccharides for efficient utilisation (Ravindran \& Jaiswal, 2016b).

Pretreatment methods are essential in increasing the efficiency of processes that involve the valorisation of lignocellulosic materials. They can broadly be classified into physical, chemical, biological and combinatorial with respect to the mechanism behind the process (Ravindran et al., 2016b). An efficient pretreatment strategy essentially should be simple, cost effective, devoid of corrosive materials and should not give rise to indigestible or inhibitory compounds. Furthermore, the fraction of interest (polysaccharide or lignin) should be safeguarded and should not result in its considerable loss (Ravindran et al., 2016b). Lastly, the whole process must be economically feasible.

The effect of several pretreatment have been presented in different studies as a part of valorisation of brewers spent grain. Macheiner et al. (2003) used microwave radiation as a pretreatment measure for BSG for increasing the efficiency of enzymatic hydrolysis. Accordingly, $25 \%$ release of saccharides was achieved after $4 \mathrm{~h}$ of incubation at $50^{\circ} \mathrm{C}$. An interesting study was published by Wolters et al. (2016) where BSG was used to produce erinacine C, a secondary metabolite produced by a medicinal fungus Hericium erinaceus. Acid hydrolysis using $0.2 \mathrm{M} \mathrm{H}_{2} \mathrm{SO}_{4}$ was employed as the pretreatment measure in this study. A novel pretreatment for BSG was devised by Zhang and Zang (2016) where they used calcined red mud to pre-treat BSG for subsequent hydrogen production. Liguori et al. (2015) utilised acid-alkali 
pretreated BSG for ethanol production with 55\% efficiency. However, a comprehensive analysis of the effects of different physical and chemical pretreatments on the composition of BSG and efficiency of enzymatic hydrolysis are yet to be performed.

Although several studies have been conducted on brewers spent grain and pretreatments, the authors could not come across any study that gave a comprehensive insight on the effect of numerous pretreatment on brewers spent grain or any lignocellulosic waste that was obtained from a single source to avoid any discrepancies or variations in observations. The authors were trying to conduct a study on the effect of pretreatment on brewers spent grain, very common agroindustry lignocellulosic waste. This study presents various attributes to the changes undergone by BSG when it was subjected to six different pretreatments. The aim of this study was to increase the cellulose content thereby facilitating better recovery of reducing sugars upon enzymatic hydrolysis. In lieu of this objective the best pretreatment strategy for maximum reducing sugar yield was determined. The pretreatments chosen in this study were well established strategies that are currently employed on a pilot scale for better utilisation of lignocellulose (Kapoor et al., 2017, Chen et al., 2013, Campbell et al., 2013). The changes in its chemical composition, structural conformation, crystallinity and thermal behaviour was analysed and compared upon subjecting BSG to different pretreatment strategies. The pretreated BSG as well as native BSG samples were then subjected to enzymatic hydrolysis using optimised parameters. The pretreatment liquor was analysed for the incidence of monosaccharides and inhibitory compounds. 


\section{Materials and methods}

Brewer's spent grain was generously donated by a local brewery in Waterford, Ireland. The BSG was dried at $60^{\circ} \mathrm{C}$ for $48 \mathrm{~h}$ and thereafter ground and sieved using a $350 \mu \mathrm{m}$ sieve. It was then stored at room temperature in a dry place for further experiments. All the chemicals such as

cellulase from Trichoderma reesei, hemicellulase from Aspergillus niger, conc. $\mathrm{H}_{2} \mathrm{SO}_{4}(99.9 \%)$, ethanol (100\%), Iron (III) chloride, anhydrous (97\%), and other chemicals required for experimentation were purchased from Sigma Aldrich, Ireland. Cellulase enzyme was purchased in liquid form. The cellulase activity was assayed by following laboratory analytical procedures for the measurement of cellulase activity devised by National Renewable Energy Laboratory (Adney \& Baker, 1996). Meanwhile, hemicellulase was in powder form and therefore was dissolved in sodium acetate buffer ( $\mathrm{pH} 4.8,500 \mathrm{mM})$ to make up a concentration of $10 \mathrm{~g} / \mathrm{l}$. The hemicellulase activity was assayed followed protocols described by Rickard and Laughlin (1980). Cellulase enzyme registered an enzyme activity of 77 FPU/ml while hemicellulase showed $72 \mathrm{U} / \mathrm{ml}$ enzyme activity.

\subsection{Screening of various pre-treatments for spent coffee waste}

\subsubsection{Dilute acid hydrolysis}

BSG (1\% w/v) was mixed with $10 \mathrm{ml}$ of sulphuric acid $(1 \%, 2 \%$ and $3 \% \mathrm{v} / \mathrm{v})$ in a $100 \mathrm{ml}$ flask. The pretreatment was conducted in an autoclave. The reaction mixture was subjected to $121^{\circ} \mathrm{C}$ for 10, 20 and $30 \mathrm{~min}$ in an autoclave (Zheng et al., 2013). The solids were separated from liquids by centrifugation at $8000 \mathrm{rpm}$ for $12 \mathrm{~min}$ after pretreatment and the supernatant was analysed for the release of any individual sugars and by-products such as acetic acid, furfural and 
hydroxymethyl furfural. The solids were dried and stored in cool and dry place until further analysis.

\subsubsection{Steam explosion}

Steam explosion of BSG was performed as described by Huang et al. (2015) with certain modifications. Five grams of BSG was moistened with de-ionized water to attain $50 \%$ moisture content (w/v). The samples that were in conical flasks were then loaded in to a stainless-steel autoclave. The temperature was raised and maintained at $121^{\circ} \mathrm{C}$ for 30 minutes after which the pressure was released by opening the pressure valve subjecting the biomass to an 'explosion'. The steam exploded BSG was collected, dried and stored in sealed plastic bags for further analysis.

\subsubsection{Ammonia Fibre Explosion}

Ammonia Fibre Explosion was performed by soaking $2.5 \mathrm{~g}$ of $\mathrm{BSG}$ with $25 \mathrm{ml}$ of $\mathrm{NH}_{4} \mathrm{OH}$. The mixture was then subjected it to high pressure and temperature in an autoclave. The experiment was carried out at $120^{\circ} \mathrm{C}$, water loading of $2.0 \mathrm{~g}$ water/g dry biomass, for a residence time of 30 min. The treated biomass was removed from the autoclave and air-dried overnight $(\approx 12 \mathrm{~h})$ in a fume hood to remove residual ammonia. The treated samples were stored in a cool and dry place (Shao et al., 2013).

\subsubsection{Pre-treatment using Ferric Chloride}

Ferric chloride pretreatment was implemented on BSG according to the procedure described by Chen et al. (2015). BSG (10\% w/v) was mixed in $50 \mathrm{ml}$ of $0.1 \mathrm{M} \mathrm{FeCl}_{3}$ in an Erlenmeyer flask and subjected to high pressure $(15 \mathrm{psi})$ and temperature $\left(120^{\circ} \mathrm{C}\right)$ for 30 minutes in an autoclave. 
The solids were separated from the liquid after allowing the mixture to cool. The solids were then washed five times with deionized water to remove any residual $\mathrm{FeCl}_{3}$. The $\mathrm{Fe}$ (III) in the liquor was precipitated by gradually neutralising the solution using $0.1 \mathrm{M} \mathrm{NaOH}$. This resulted in the precipitation of residual $\mathrm{FeCl}_{3}$. The salt free liquor was then subjected to HPLC analysis to identify and quantify any individual sugars present as well as hydroxyl-5-methyl furfural and furfural content. The solids were dried and stored for enzymatic hydrolysis and further analysis.

\subsubsection{Organosolv Pre-treatment}

Organosolv pretreatment was performed as described by Ostovareh et al. (2015) with minor modifications. $1 \%$ dry BSG was mixed in $25 \mathrm{ml}$ of ethanol-water mixture $(60 \%$ ethanol (v/v) $)$ in an Erlenmeyer flask. In all experiments, $1 \%$ of sulphuric acid (w/w) per gram substrate was added as a catalyst. The pretreatment reaction was conducted at $100{ }^{\circ} \mathrm{C}$ and the temperature was maintained for $30 \mathrm{~min}$. The contents in the flasks were quickly cooled to room temperature by placing them in an ice chamber. The contents were centrifuged at $8000 \mathrm{rpm}$ for 12 minutes to separate the solids from the liquids. The solids were washed with $250 \mathrm{ml}$ of $50 \%$ ethanol mixture to extract the soluble products into the liquid phase. The pre-treated substrate was then washed several times with distilled water until $\mathrm{pH} 7$ was obtained. The pretreated $\mathrm{BSG}$ was dried at $60^{\circ} \mathrm{C}$ overnight and stored in a cool and dry place until further analysis. Ethanol was evaporated and retrieved from the liquid fraction and recovered by condensation leaving behind a precipitate which mainly contained lignin.

\subsubsection{Microwave assisted alkali (MAA) pre-treatment}

MAA was carried out following the procedure described by Binod et al. (2012) with minor modifications. A domestic microwave (Sharp/R-269 KM, Sharp Electronics Ltd, Manchester, 
UK.) with a maximum output power of $800 \mathrm{~W}$ was employed for this purpose. $1 \%(\mathrm{w} / \mathrm{v})$ biomass was loaded to $0.5 \% \mathrm{NaOH}(\mathrm{w} / \mathrm{v})$ solution in a stoppered flask and subjected to microwave radiation at varying power settings of $400 \mathrm{~W}, 560 \mathrm{~W}$ and $800 \mathrm{~W}$ for different residence time varying from $30 \mathrm{~s}, 60 \mathrm{~s}$ and $120 \mathrm{~s}$. After pre-treatment, the biomass was thoroughly washed with distilled water till pH 6.0 and dried in air. The dried solid residue was used for enzymatic hydrolysis and compositional analysis.

\subsection{Compositional analysis}

Compositional analysis of the pretreated and native BSG samples were performed by two stage acid hydrolysis according to National Renewable Energy Laboratory (NREL) protocol (Sluiter et al., 2005). The BSG samples were subjected to acid hydrolysis using $72 \% \mathrm{H}_{2} \mathrm{SO}_{4}$ at $30^{\circ} \mathrm{C}$ for 60 min. The mixture was then diluted to $4 \% \mathrm{H}_{2} \mathrm{SO}_{4}$ concentration by adding deionised water and autoclaved for $60 \mathrm{~min}$. The solids were filtered using a filtration crucible and dried at $105^{\circ} \mathrm{C}$ for $48 \mathrm{~h}$ to remove all the moisture content or until constant weight was achieved. The dried solids were then burned in blast furnace for $24 \mathrm{~h}$ at $595^{\circ} \mathrm{C}$ to obtain acid insoluble lignin. The acid soluble lignin content in the liquid was determined using spectrophotometry at $205 \mathrm{~nm}$.

The reducing sugar concentration in the hydrolysate was estimated by dinitrosalicylic acid (DNS) method (Miller, 1959). The presence and quantification of monosaccharides was done in an Allaince HPLC (Waters, e2695 Separation module) using a Rezex ROA-Organic acid H+ (8\%) column, (350 x $7.8 \mathrm{~mm}$; Phenomenex, UK) with $5 \mathrm{mM} \mathrm{H}_{2} \mathrm{SO}_{4}$ as the mobile phase at $65^{\circ} \mathrm{C}$ maintaining a flow rate of $0.6 \mathrm{ml} / \mathrm{min}$ (Jaiswal et al., 2012). The HPLC system was equipped with an autosampler, degasser and isocratic pump. A refractive index detector was used for the detection of the afore mentioned compounds. A guard column of the same kind was used along 
with the regular column. This was kept outside the compartment to avoid overheating beyond the manufacturers recommended limit.

\subsection{Enzymatic hydrolysis}

The enzymatic hydrolysis of BSG was performed by employing commercially available cellulase and hemicellulase purchased from Sigma Aldrich, Ireland. The hydrolysis parameters were determined employing response surface methodology using STATGRAPHICS Centurion XV software (Table 1). A central composite design was created which included five parameters and five levels with five replicating centre points. The parameters considered for this study included biomass loading, cellulase, hemicellulase, $\mathrm{pH}$ and time. Designated amounts of BSG (subjected to alkali assisted microwave pretreatment), cellulase (77.08 FPU/ml), and hemicellulase (72.23 $\mathrm{U} / \mathrm{ml})$ was mixed in sodium citrate buffer $(0.05 \mathrm{M})$ and distilled water to maintain a reaction volume of $10 \mathrm{ml}$ as presented in Table 1 . The temperature for all the experiments were set at $50^{\circ} \mathrm{C}$. The reactions were carried out for different time periods $(24,48,72,96$ and 120) (Table 1). On completion of each experiment the hydrolysate was collected after filtration and the reducing sugar content was measured using DNS method.

\subsection{Individual sugar, inhibitor and organic acid analysis}

The liquor obtained after each pretreatment was analysed for the presence of monosaccharides organic acids, acetyl or any inhibitory compounds such as furfural and hydroxymethyl furfural. This was done by following the methodology described in section 2.2. 


\subsection{Characterization of native and pre-treated substrate}

\subsubsection{Scanning electron microscopy}

The morphological structure and the effect of pretreatment on BSG were analysed by performing FE-SEM. Dried samples of the untreated and pretreated BSG were subject to FE-SEM. FE-SEM analysis was performed using a Hitachi SU-70 Field emission microscope operating at electron beam energy of $0.5 \mathrm{keV}$ (Raghavi et al., 2016).

\subsubsection{X-ray diffraction}

X-ray diffraction studies were conducted to analyse the changes in crystallinity of brewer's spent grain imparted by each pretreatment. This was done using a Siemens D-500 X-ray diffractometer with diffraction angles spanned from $2 \theta=5^{\circ}-50^{\circ}$. The radiation was generated at a voltage of 40 $\mathrm{kV}$ and current of $30 \mathrm{~mA}$ using $\mathrm{Cu} \mathrm{K} \alpha$ as the radiation source $(\lambda=0.154 \mathrm{~nm})$ (Binod et al., 2012).

\subsubsection{FTIR analysis}

FTIR spectroscopy studies were performed to observe any changes in the composition as a reflection of the variations in the functional groups in pretreated BSG at the backdrop of its raw counterpart. A Perkin Elmer Spectrum GX FT-IR (UATR) Microscope (USA) was employed for this study The FTIR spectra was recorded from 4000 to $400 \mathrm{~cm}^{-1}$ with 32 scans at a resolution of $0.3 \mathrm{~cm}^{-1}$ in transmission mode (Raghavi et al., 2016)

\subsubsection{Thermal behaviour}

Differential scanning calorimetry (DSC) was used to study the changes in the thermal behaviour of brewer spent grain before and after pretreatment. Each BSG sample (55 $\mathrm{mg}$ ) was taken in an 
aluminium pan with an empty pan used as a reference. All the measurements were carried out between $25^{\circ} \mathrm{C}$ and $500^{\circ} \mathrm{C}$ with a linear increase of $10^{\circ} \mathrm{C} /$ minute as described by Ballesteros et al. (2014) and Ferraz et al. (2013). Shimadzu DSC-60 installed with TA-60WS software was the equipment used for this purpose.

\subsection{Statistical analysis}

All the analytical experiments were carried out in triplicate and results are expressed as mean values \pm standard deviation (SD). Central Composite Design (CCD) (conducted in random order) of the experiment was applied for the estimation of the regression parameters to fit a seconddegree polynomial regression model for a given response. A polynomial, as given by equation (1), quantifies relationships among the estimated response $\mathrm{y}$ and a number of independent variables Xi (biomass loading, cellulase loading, hemicellulase loading, pH and incubation time), $\beta$ are regressors associated with the model:

$$
y=\beta_{0}+\sum_{i=1}^{5} \beta_{i} X_{i}+\sum_{i=1}^{5} \sum_{j=1}^{5} \beta_{i j} X_{i} X_{j}+\sum_{i=1}^{5} \beta_{i i} X_{i}^{2}
$$

The regressors $\beta_{0}, \beta_{i}, \beta_{i i}$ and $\beta_{i j}$ are the model constant, linear coefficient, quadratic and crossproduct coefficients, provide a quantitative measure of the significance of linear effects, quadratic of factors and interactions between factors. The regression analysis and analysis of variance (ANOVA) were carried. Values of $\mathrm{P}<0.05$ were considered as statistically significant. The significant differences between each pretreatment with respect to the components of BSG was analysed by performing analysis of variance (ANOVA) and multiple comparisons (Fischer's 
least significant difference test). All statistical analyses were carried out using out using the STATGRAPHICS Centurion XV.

\section{Results and discussion}

\subsection{Optimisation of enzymatic hydrolysis parameters using RSM}

The parameters for enzymatic hydrolysis of BSG was optimised by using response surface methodology. This ensured that maximum reducing sugar was released using the RSM optimised hydrolysis conditions. The total reducing sugars obtained after the 30 experiments were conducted have been listed in table 2. The model was compared based on coefficient of determination $\left(R^{2}\right)$ and adjusted coefficient of determination $\left(R^{2}\right.$-adj). $R^{2}$ is regression of sum of squares proportional to the sum of squares. The value of $\mathrm{R}^{2}$ ranges from 0 to 1 and a value closer to one indicates that the model is accurate. An $R^{2}$ value of 98.92 and adj- $R^{2}$ value of 96.5 illustrated that the model adequately fitted the data. The data obtained from the experiment were fitted into a second order polynomial equation. The polynomial equation depicted the relationship between various parameters used in the model and is mentioned below:

Reducing sugar $(\mathrm{mg} / \mathrm{ml})=0.711+3.05458 X_{I^{-}} 0.002755 X_{2}+0.00879306 X_{3}+0.211115$

$$
\begin{aligned}
& X_{4}+1.38194 X_{5}+0.2375 X_{1}^{2}-0.0833 X_{1} X_{2}+0.0239 X_{1} X_{3}- \\
& 0.0052 X_{1} X_{4}+0.0312 X_{1} X_{5}+0.0158 X_{2}^{2}+0.0166 X_{2} X_{3}-0.0371 X_{2} X_{4} \\
& +0.0011 X_{2} X_{5}-0.0352 X_{3}^{2}+0.0289 X_{3} X_{4}+0.0104 X_{3} X_{5}-0.0417 X_{4}^{2}- \\
& 0.0126 X_{4} X_{5}-0.0881 X_{5}^{2}
\end{aligned}
$$


$X_{1}, X_{2}, X_{3}, X_{4}$ and $X_{5}$ represent biomass loading, cellulase, hemicellulase, $\mathrm{pH}$ and incubation time respectively. Analysis of variance (ANOVA) was used to determine the significance of the coefficients of the models. The ANOVA table indicated that 7 effects had $\mathrm{P}$ value less than 0.05 rendering them significantly different from the confidence interval spanning from zero to $95.0 \%$. This also illustrated that these factors had considerable influence on the reducing sugar yield. All the linear coefficients were found to have a positive effect on the reducing sugar yield. However, positive significant interaction effects on reducing sugar release were exhibited only by biomass loading and time.

Three-dimensional response plots were generated to understand the interactions between different variables as well as to determine the optimal level of each variable for maximum response (Fig. 1). This gave further insights on the interactions between the five factors tested. The contour plots were indicative of significant interaction between each parameter considered in this study. The highest point on the three-dimensional plots represents the optimum conditions for maximum reducing sugar release. Accordingly, a maximum reducing yield was observed with high biomass loading $(1 \mathrm{~g} / 10 \mathrm{ml})$, cellulase $(158.76 \mu \mathrm{l} / 10 \mathrm{ml})$, hemicellulase $(153.3 \mu \mathrm{l}$ $/ 10 \mathrm{ml}), \mathrm{pH}(5.4)$ and an incubation time (120h). The model predicted the maximum sugar yield to be $19.42 \mathrm{mg} / \mathrm{ml}$ when using the optimised parameters for enzymatic hydrolysis. A reducing sugar concentration of $18.61 \pm 0.5 \mathrm{mg} / \mathrm{ml}$ confirmed that the model was valid for the enzymatic hydrolysis of BSG due to little disparity $(<5 \%)$ between predicted and observed values.

\subsection{Influence of pre-treatments on composition of BSG and reducing sugar yield}

Pretreatments breakdown lignocellulose creating disorder in an otherwise orderly structure with or without the removal of inherent components. The effect of each pretreatment varies according 
to its mode of action (for example: physical, chemical, physico-chemical and biological) (Ravindran \& Jaiswal, 2016b). The final chemical composition of the biomass post pretreatment is an important factor that governs the efficiency of enzymatic hydrolysis. For a lignocellulosic substrate to be effectively used in a bioconversion process it is necessary to relatively expose cellulose fibres along with possible removal of hemicellulose and lignin fractions. BSG was comprised of $19.21 \mathrm{~g}$ of cellulose (glucose), $26.94 \mathrm{~g}$ of hemicellulose and $30.48 \mathrm{~g}$ of lignin per $100 \mathrm{~g}$ of dry biomass (Table 3 ). The values obtained were more or less similar to composition of BSG described elsewhere (Robertson et al., 2010). Any variation can be attributed to the source of collection of BSG. The composition of BSG can vary with respect to the barley variety, harvest time and mashing conditions (Forssell et al., 2008). After each pretreatment the biomass was subjected to chemical composition analysis. Furthermore, all the pretreated samples were subjected to hydrolysis employing polysaccharide hydrolysing enzymes and optimised parameters.

In general, all the pretreatments tested were effective in increasing the efficiency of enzymatic hydrolysis. This was evident from the increase in reducing sugar release of pretreated BSG samples (Fig. 2). Dilute acid hydrolysis was conducted for BSG following different experimental settings. The pretreated BSG was weighed to examine if there was any weight loss after pretreatment. There was almost 50\% loss in biomass post pretreatment. The effect of acid concentration and reaction time on the effectiveness of acid hydrolysis for BSG was studied by employing three acid concentrations $(1 \%, 2 \%$ and $3 \%)$ and three different time settings $(10,20$, and $30 \mathrm{~min}$ ). The solids obtained after pretreatment were subjected to enzymatic hydrolysis. Longer treatment times resulted in reduction in reducing sugar yield. Best results were achieved when $\mathrm{BSG}$ was treated with $3 \% \mathrm{H}_{2} \mathrm{SO}_{4}$ for $20 \mathrm{~min}(208.78 \mathrm{mg} / \mathrm{g}$ of $\mathrm{BSG})$. Compositional 
analysis of the biomass revealed that subjecting BSG to dilute acid hydrolysis resulted in the increase in cellulose content $(35.43 \mathrm{~g} / 100 \mathrm{~g}$ of BSG) as well as removal of considerable fractions of hemicellulose. This was evident in the reduction in the xylan, galactan, mannan and arabinan content. Also, there was reduction in the acid soluble lignin fraction (4.42g/100g of BSG).

MAA pretreatment was found to be the most effective pretreatment for BSG. Three different power settings $(400 \mathrm{~W}, 560 \mathrm{~W}$ and $800 \mathrm{~W})$ and three time durations (30s, 60s, 120s) were employed to study the individual effects on each parameter on reducing sugar yield. Microwaving BSG at $400 \mathrm{WW}$ for $60 \mathrm{~s}$ was found to be the most appropriate setting for this pretreatment strategy. After the pretreatment, the cellulose content in the BSG increased (43.67g/100g dry wt.) while the hemicellulose and lignin fractions diminished (Table 3) which was by far the best pretreatment strategy for BSG among all the treatments studied. Furthermore, subjecting BSG to microwave treatment, presence of alkali resulted in highest reducing sugar yield (228.78 mg/g of BSG). The difference in composition brought about this pretreatment was found to be significantly different from other pretreatments when it came to cellulose and lignin. However, no significant difference was brought about by microwave assisted alkali treatment in terms of xylan content (similar to AFEX pretreatment) and arabinan content (similar to ferric chloride pretreatment).

Steam explosion of BSG did not result in an increase of the cellulose content or substantial lignin removal from the biomass. This was evident from Table 3 were it was observed that BSG obtained after subjecting it to this strategy was not significantly different from native BSG in terms of cellulose content and acid soluble lignin content. However, there was an increase in reducing sugar content post enzymatic hydrolysis compared to native BSG. The mode of action 
of this pretreatment resulted in structural disruption of lignocellulose by sudden decompression thereby revealing internal structures for enzymatic digestion (Jönsson \& Martín, 2016). Steam explosion was conducted in an autoclave which limited the temperature and pressure used in this study to $121^{\circ} \mathrm{C}$ and 15 psi respectively. A reducing sugar concentration of $194 \mathrm{mg} / \mathrm{g}$ of BSG was obtained when steam-exploded BSG was subjected to enzymatic hydrolysis. AFEX pretreatment resulted in the melting of lignin and re-deposition of the same on the biomass. After treatment, BSG appeared to be dark in colour due to this phenomenon. The residual lignin prevents the evaporation of water and residual ammonia. Hence the pretreated BSG was left in the fume hood overnight for maximum ammonia removal. Similar observations were reported by Lee et al. (2010) when they subjected coastal Bermuda grass to AFEX pretreatment. The lignin content removal attained by this pretreatment was not significant enough when compared to native BSG. Moreover, this pretreatment was similar to organosolv pretreatment with respect to galactan content and arabinan content. AFEX pretreatment resulted in a reducing sugar release of 211.2 $\mathrm{mg} / \mathrm{g}$ of BSG post enzymatic hydrolysis.

Organosolv pretreatment employs primary alcohols along with high temperatures are a pretreatment measure for delignification of plant biomass. Methanol and ethanol are employed for this purpose due to their low cost and availability. The advantage of this pretreatment is that solvent and the lignin dissolved by it can be recovered using simple distillation methods. (Zhao et al., 2009). The acid catalyst used in organosolv process is corrosive in nature and can give rise to inhibitory compounds when reacting with carbohydrate fractions in lignocellulose. However, in this case no inhibitory compounds were formed. Furthermore, there was considerable delignification $(16.89 \mathrm{~g} / 100 \mathrm{~g}$ of BSG) and increment in cellulose content $(26.42 \mathrm{~g} / 100 \mathrm{~g}$ of BSG). 
Reducing sugar yields amounted to $204.3 \mathrm{mg} / \mathrm{g}$ of substrate when BSG pretreated using organosolv strategy was subjected to enzymatic hydrolysis.

The effect of ferric chloride pretreatment was generally insignificant with respect to delignification. This pretreatment results in the degradation of the polysaccharide fraction into the pretreatment liquor (Chen et al., 2015). There was obvious loss in weight of biomass after pretreatment. The cellulose content in the pretreated biomass amounted to $17.99 \mathrm{~g} / 100 \mathrm{~g}$ of BSG while the hemicellulose content was found to be $9.55 \mathrm{~g} / 100 \mathrm{~g}$ of BSG. The total lignin content (26.3 mg/100g of BSG) remained the same more or less compared to raw BSG. $199.4 \mathrm{mg} / \mathrm{g}$ of reducing sugar was obtained after enzymatic hydrolysis of BSG pretreated with ferric chloride.

\subsection{Individual sugar, furfural, hydroxymethyl furfural and organic acid analysis}

The hydrolysate obtained after the enzymatic hydrolysis experiment was analysed to identify reducing sugars released from BSG. The liqueur obtained after each pretreatment were subjected to HPLC analysis to identify the presence of individual sugars as well as inhibitory compounds such as furfural and hydroxymethyl furfural. All the pretreatments tested resulted in the release of small amounts of different component sugars into the pretreatment liquor. These sugars were identified to be arabinose, xylose, mannose, galactose and glucose. Glucose and xylose were found to be the most abundant monosaccharides in BSG making this type of food waste a good feedstock for bioethanol production (Robertson et al., 2010). A notable observation was the formation of furfural when BSG was subjected to dilute acid pretreatment $(1.7 \mathrm{~g} / 100 \mathrm{~g}$ of $\mathrm{BSG})$. Furfural is formed as degradation product of xylose component in lignocellulose. A study conducted by Djioleu and Carrier (2016) revealed that the furfural formation from xylose is directly linked to the temperature applied during dilute acid hydrolysis. 


\subsection{SEM, XRD and FTIR profiles of untreated and pre-treated brewers spent grain}

SEM analysis was performed to observe the physical modifications imparted by MAA pretreatment in the backdrop of native BSG as this pretreatment was found to be the most effective following composition analysis. The untreated brewers' spent grain has a crumbled, nonporous surface with different layer like formations. The MAA pretreated BSG exhibited a sieve-like structure with uneven and non-uniform holes formed on the surface. This might be due to the removal of external fibres. Similar observations were reported by Binod et al. (2012) in a study involving MAA pretreatment of sugar cane bagasse. Individual fibers were observed on the surface of BSG indicating a breakdown in integral structure resulting in an increase in surface area. This facilitates enhanced hydrolysis or cellulose in BSG due to increased accessibility. Similar findings were reported by Santos et al. (2015) in study where BSG was subjected to alkali treatment.

Fourier Transform Infrared spectroscopy (FTIR) is used to characterise the chemical structure of lignocellulosic biomass by identifying the functional groups present in the sample. The peak at $1739 \mathrm{~cm}^{-1}$ represents ester bonds or carboxylic linkages in lignin and hemicellulose. This peak was evident in untreated BSG but diminished in pretreated BSG samples according to the effectiveness of the pretreatment. The peak $1526 \mathrm{~cm}^{-1}$ represents $\mathrm{C}=\mathrm{C}$ bonds in the aromatic ring of lignin. On the other hand, the peak observed at $1247 \mathrm{~cm}^{-1}$ corresponds to aryl-alkyl ether bonds (C-O-C). While these bands were present (albeit less prominent) in steam exploded, organosolv, ferric chloride and dilute acid pretreated BSG no trace of it was observed in AFEX and MAA pretreated samples. The peaks $895 \mathrm{~cm}^{-1}$ and $1053 \mathrm{~cm}^{-1}$ are directly related to the C-O stretching and $\mathrm{C}-\mathrm{H}$ vibrations that are a characteristic of cellulose content in BSG. All the BSG 
samples (pretreated and native alike) exhibited these peaks in their respective spectra (Santos et al., 2015).

The inherent components in lignocellulosic biomass can be crystalline or amorphous in nature. Crystallinity in any plant biomass is attributed by cellulose. Hemicellulose and lignin are

amorphous in nature. The crystallinity of all the BSG samples was assessed by X-ray diffraction. Increase in crystallinity is an indication of increase of cellulose content and in turn effectiveness of the pretreatment (Binod et al., 2012). The increase in peaks at the $15^{\circ}$ and $22^{\circ}$ is caused by the disorderliness of the structure due to the effects of pre-treatments (Pereira et al., 2011). XRD spectra of all the pretreated BSG revealed an absence in distinct amorphous regions. This can be attributed to the attrition of hemicellulose and lignin fractions in pretreated BSG samples. MAA pretreated BSG exhibited highest crystallinity compared to all the other pretreated BSG. Comparatively, BSG samples that underwent ferric chloride pretreatment exhibited lowest crystallinity which may be explained by the low cellulose content observed after pretreatment.

\subsection{Thermal behaviour study using differential scanning colorimetry}

Differential scanning calorimetry (DSC) is a technique used to study the behaviour of materials as a function of temperature or time. Melting points, crystallisations and chemical reactions are some of the properties that can be studied using DSC. This technique measures the heat flow in a sample when it is heated, cooled or held at a constant temperature. A sample may undergo various phase changes during heating or cooling. The temperature of the sample was raised from $20^{\circ} \mathrm{C}$ to $500^{\circ} \mathrm{C}$ at a heating rate of $10^{\circ} \mathrm{C} / \mathrm{min}$ at constant nitrogen atmosphere. An empty aluminium pan was used as reference. Pretreated samples such as steam explosion, dilute acid hydrolysis, ferric chloride pretreatment and organosolv, along with native BSG exhibited a 
similar trend in their thermogram suggesting that they were similar in their composition. An exothermic event can be observed for all the samples with extensive mass loss between a temperature range of $20^{\circ} \mathrm{C}$ to $320^{\circ} \mathrm{C}$. This temperature range marked several processes which gave rise to compounds such as carbon monoxide, carbon dioxide and other pyrolysis products. Some of the processes that occur within this temperature range is the degradation of lignin by the fragmentation of linkages between the phenyl propane units, protein degradation and decomposition of the polysaccharide fraction (Alriols et al., 2009; Sun et al., 2001). This was followed by an endothermic event that spanned between the temperature range of $300^{\circ} \mathrm{C}$ to $430^{\circ} \mathrm{C}$ and beyond. Microwave pretreated BSG sample exhibited a thermal behaviour which included a crystallisation peak between the temperature range of $360^{\circ} \mathrm{C}$ to $480^{\circ} \mathrm{C}$. Interestingly, the thermogram of AFEX pretreated BSG was unique due to the sharp fall in heat flow which represented a transient ending at a very early stage of the experiment $\left(355^{\circ} \mathrm{C}\right)$.

Serious issues such as the energy crisis coupled by environmental issues such as dwindling resources as well as global warming has called for wide-scale innovation in the utilisation of renewable resources such as lignocellulosic agro-waste. This type of waste holds great importance in this regard due to their abundance and renewable nature and being comparatively inexpensive. Lignocellulosic waste has untapped potential to replace fossil fuels as well as acting as raw materials to produce bio-based chemicals. For all this to be achieved extensive research and innovation must be carried out in the field of pretreatments to make industrial processes based on lignocellulose economically viable. 


\section{Conclusion}

MAA pretreatment was highly successful as a pretreatment for BSG yielding $228.78 \mathrm{mg}$ of reducing sugar /g of BSG after enzymatic hydrolysis. AFEX was found to be the second best pretreatment for BSG in terms of reducing sugar yield $(211.2 \mathrm{mg} / \mathrm{g}$ of BSG). Dilute acid pretreatment although resulting in high sugar yield $(208.8 \mathrm{mg} / \mathrm{g}$ of BSG) gave rise to furfural $(1.7 \mathrm{~g} / 100 \mathrm{~g}$ of BSG). Crystallinity studies revealed that crystallinity of pretreated BSG samples (except ferric chloride pretreatment) were more than the native BSG samples suggesting increase in cellulose content. All these results suggested that BSG is a potential feedstock to produce value added products.

\section{Acknowledgement}

The authors would like to acknowledge the funding from Dublin Institute of Technology (DIT), Dublin, Ireland under the Fiosraigh Scholarship programme, 2014.

\section{References}

1. Adney, B., Baker, J. 1996. Measurement of cellulase activities. Lab. Anal. Proced. 6, 1996.

2. Alriols, M.G., Tejado, A., Blanco, M., Mondragon, I., Labidi, J. 2009. Agricultural palm oil tree residues as raw material for cellulose, lignin and hemicelluloses production by ethylene glycol pulping process. Chem. Eng. J. 148, 106-114.

3. Binod, P., Satyanagalakshmi, K., Sindhu, R., Janu, K.U., Sukumaran, R.K., Pandey, A. 2012. Short duration microwave assisted pretreatment enhances the enzymatic saccharification and fermentable sugar yield from sugarcane bagasse. Renew. Energ. 37, 109-116.

4. Chen, L., Chen, R., Fu, S. 2015. FeCl3 pretreatment of three lignocellulosic biomass for ethanol production. ACS Sustain. Chem. Eng. 3, 1794-1800. 
5. Djioleu, A., Carrier, D.J. 2016. Effects of dilute acid pretreatment parameters on sugar production during biochemical conversion of switchgrass using a full factorial design. ACS Sustain. Chem. Eng. 4, 4124-4130.

6. Ferraz, E., Coroado, J., Gamelas, J., Silva, J., Rocha, F., Velosa, A. 2013. Spent brewery grains for improvement of thermal insulation of ceramic bricks. J. Mater. Civil Eng. 25, 1638-1646.

7. Forssell, P., Kontkanen, H., Schols, H.A., Hinz, S., Eijsink, V.G.H., Treimo, J., Robertson, J.A., Waldron, K.W., Faulds, C.B., Buchert, J. 2008. Hydrolysis of Brewers' spent grain by carbohydrate degrading enzymes. J. Inst. Brew. 114, 306-314.

8. Huang, Y., Wei, X., Zhou, S., Liu, M., Tu, Y., Li, A., Chen, P., Wang, Y., Zhang, X., Tai, H., Peng, L., Xia, T. 2015. Steam explosion distinctively enhances biomass enzymatic saccharification of cotton stalks by largely reducing cellulose polymerization degree in $G$. barbadense and G. hirsutum. Bioresour. Technol. 181, 224-230.

9. Jaiswal, A.K., Gupta, S., Abu-Ghannam, N. 2012. Optimisation of lactic acid fermentation of York cabbage for the development of potential probiotic products. Int. J. Food Sci. Technol. $47,1605-1612$.

10. Jönsson, L.J., Martín, C. 2016. Pretreatment of lignocellulose: Formation of inhibitory byproducts and strategies for minimizing their effects. Bioresour. Technol. 199, 103-112.

11. Lee, J.M., Jameel, H., Venditti, R.A. 2010. A comparison of the autohydrolysis and ammonia fiber explosion (AFEX) pretreatments on the subsequent enzymatic hydrolysis of coastal Bermuda grass. Bioresour. Technol. 101, 5449-5458.

12. Liguori, R., Soccol, C., Porto de Souza Vandenberghe, L., Woiciechowski, A., Faraco, V. 2015. Second generation ethanol production from Brewers' spent grain. Energies, 8, 2575. 
13. Kapoor, M., Soam, S., Agrawal, R., Gupta, R.P., Tuli, D.K. and Kumar, R. 2017 Pilot scale dilute acid pretreatment of rice straw and fermentable sugar recovery at high solid loadings, Bioresour. Technol. 224, 688-693.

14. Chen, W. H., Tsai, C. C., Lin, C. F., Tsai P. Y., Hwang W. S. 2013 Pilot-scale study on the acid-catalyzed steam explosion of rice straw using a continuous pretreatment system, Bioresour. Technol. 128, 297-304

15. Campbell, T. J., Teymouri, F., Bals, B., Glassbrook, J., Nielson, C. D., \& Videto, J. 2013. A packed bed Ammonia Fiber Expansion reactor system for pretreatment of agricultural residues at regional depots. Biofuels, 4, 23-34.

16. Macheiner, D., Adamitsch, B.F., Karner, F., Hampel, W.A. 2003. Pretreatment and hydrolysis of Brewer's spent grains. Eng. Life Sci. 3, 401-405.

17. Miller, G.L. 1959. Use of dinitrosalicylic acid reagent for determination of reducing sugar. Anal. Chem. 31, 426-428.

18. Mussatto, S.I., Dragone, G., Roberto, I.C. 2006. Brewers' spent grain: generation, characteristics and potential applications. J. Cereal Sci. 43, 1-14.

19. Ostovareh, S., Karimi, K., Zamani, A. 2015. Efficient conversion of sweet sorghum stalks to biogas and ethanol using organosolv pretreatment. Ind. Crops Prod. 66, 170-177.

20. Pereira, P.H.F., Voorwald, H.C.J., Cioffi, M.O.H., Mullinari, D.R., Da Luz, S.M., Da Silva, M.L.C.P. 2011. Sugarcane bagasse pulping and bleaching: Thermal and chemical characterization. BioResources, 6, 2471-2482.

21. Raghavi, S., Sindhu, R., Binod, P., Gnansounou, E., Pandey, A. 2016. Development of a novel sequential pretreatment strategy for the production of bioethanol from sugarcane trash. Bioresour. Technol. 199, 202-210. 
22. Ravindran, R., Jaiswal, A.K. 2016a. Exploitation of food industry waste for high-value products. Trend. Biotechnol. 34, 58-69.

23. Ravindran, R., Jaiswal, A.K. 2016b. A comprehensive review on pre-treatment strategy for lignocellulosic food industry waste: challenges and opportunities. Bioresour. Technol. 199, 92-102.

24. Ravindran, R., Jaiswal, A.K. 2016c. Microbial enzyme production using lignocellulosic food industry wastes as feedstock: A review. Bioeng. 4, 30.

25. Rickard, P., Laughlin, T. 1980. Detection and assay of xylanolytic enzymes in a Cellulomonas isolate. Biotechnol. Lett. 2, 363-368.

26. Robertson, J.A., I'Anson, K.J.A., Treimo, J., Faulds, C.B., Brocklehurst, T.F., Eijsink, V.G.H., Waldron, K.W. 2010. Profiling brewers' spent grain for composition and microbial ecology at the site of production. LWT - Food Sci. Technol. 43, 890-896.

27. Santos, D.M.d., Bukzem, A.d.L., Ascheri, D.P.R., Signini, R., Aquino, G.L.B.d. 2015. Microwave-assisted carboxymethylation of cellulose extracted from Brewer's spent grain. Carbohydr. Polym. 131, 125-133.

28. Shao, Q., Cheng, C., Ong, R.G., Zhu, L., Zhao, C. 2013. Hydrogen peroxide presoaking of bamboo prior to AFEX pretreatment and impact on enzymatic conversion to fermentable sugars. Bioresour. Technol. 142, 26-31.

29. Sluiter, A., Ruiz, R., Scarlata, C., Sluiter, J., Templeton, D. 2005. Determination of extractives in biomass. Lab. Anal. Proced. (LAP), 1617.

30. Sun, R., Lu, Q., Sun, X.F. 2001. Physico-chemical and thermal characterization of lignins from Caligonum monogoliacum and Tamarix spp. Polym. Degrad. Stab. 72, 229-238. 
31. Wolters, N., Schabronath, C., Schembecker, G., Merz, J. 2016. Efficient conversion of pretreated Brewer's spent grain and wheat bran by submerged cultivation of Hericium erinaceus. Bioresour. Technol. 222, 123-129.

32. Xiros, C., Christakopoulos, P. 2012. Biotechnological potential of Brewers spent grain and its recent applications. Waste Biomass Valorization 3, 213-232.

33. Zhang, J., Zang, L. 2016. Enhancement of biohydrogen production from Brewers' spent grain by calcined-red mud pretreatment. Bioresour. Technol. 209, 73-79.

34. Zhao, X., Cheng, K., Liu, D. 2009. Organosolv pretreatment of lignocellulosic biomass for enzymatic hydrolysis. Appl. Microbiol. Biotechnol. 82, 815.

35. Zheng, Y., Lee, C., Yu, C., Cheng, Y.-S., Zhang, R., Jenkins, B.M., VanderGheynst, J.S. 2013. Dilute acid pretreatment and fermentation of sugar beet pulp to ethanol. Appl. Energ. $105,1-7$. 


\section{$\underline{\text { Figure Captions }}$}

Fig 1. Response surface plots representing the effect of independent variables on reducing sugar yield (1a) the effect of cellulase and time on reducing sugar yield when the response surface is fixed at biomass loading $=0.6 \mathrm{~g} / 10 \mathrm{ml}$, hemicellulase $=180 \mu \mathrm{l} / 10 \mathrm{ml}$ and $\mathrm{pH}=6.0$; (1b) representing the effect of time and biomass loading on reducing sugar yield, when the response surface is fixed at cellulase loading $=450 \mu \mathrm{l} / 10 \mathrm{ml}$, hemicellulase $=180 \mu \mathrm{l} / 10 \mathrm{ml}, \mathrm{pH}=$ 6.0; (1c) representing the effect of cellulase and hemicellulase loading on reducing sugar yield, when the response surface is fixed at biomass loading $=0.6 \mathrm{~g} / 10 \mathrm{ml}$, time $=72 \mathrm{~h}, \mathrm{pH}=6.0$; (1d) representing the effect of hemicellulase and biomass loading on reducing sugar yield, when the response surface is fixed at cellulase loading $=450 \mu \mathrm{l} / 10 \mathrm{ml}$, time $=72 \mathrm{~h}, \mathrm{pH}=6.0$; (1e) representing the effect of biomass and cellulase loading on reducing sugar yield, when the response surface is fixed at hemicellulase loading $=180 \mu \mathrm{l} / 10 \mathrm{ml}$, time $=72 \mathrm{~h}$, and $\mathrm{pH}=6.0$ (1f) representing the effect of incubation time and $\mathrm{pH}$ on reducing sugar yield, when the response surface is fixed at biomass loading $=0.6 \mathrm{~g} / 10 \mathrm{ml}$, hemicellulase loading $=180 \mu \mathrm{l} / 10 \mathrm{ml}$ and cellulase loading $=450 \mu 1 / 10 \mathrm{ml}$.

Fig 2. Total reducing sugar released (mg/g of BSG) after enzymatic hydrolysis of pretreated and native BSG 

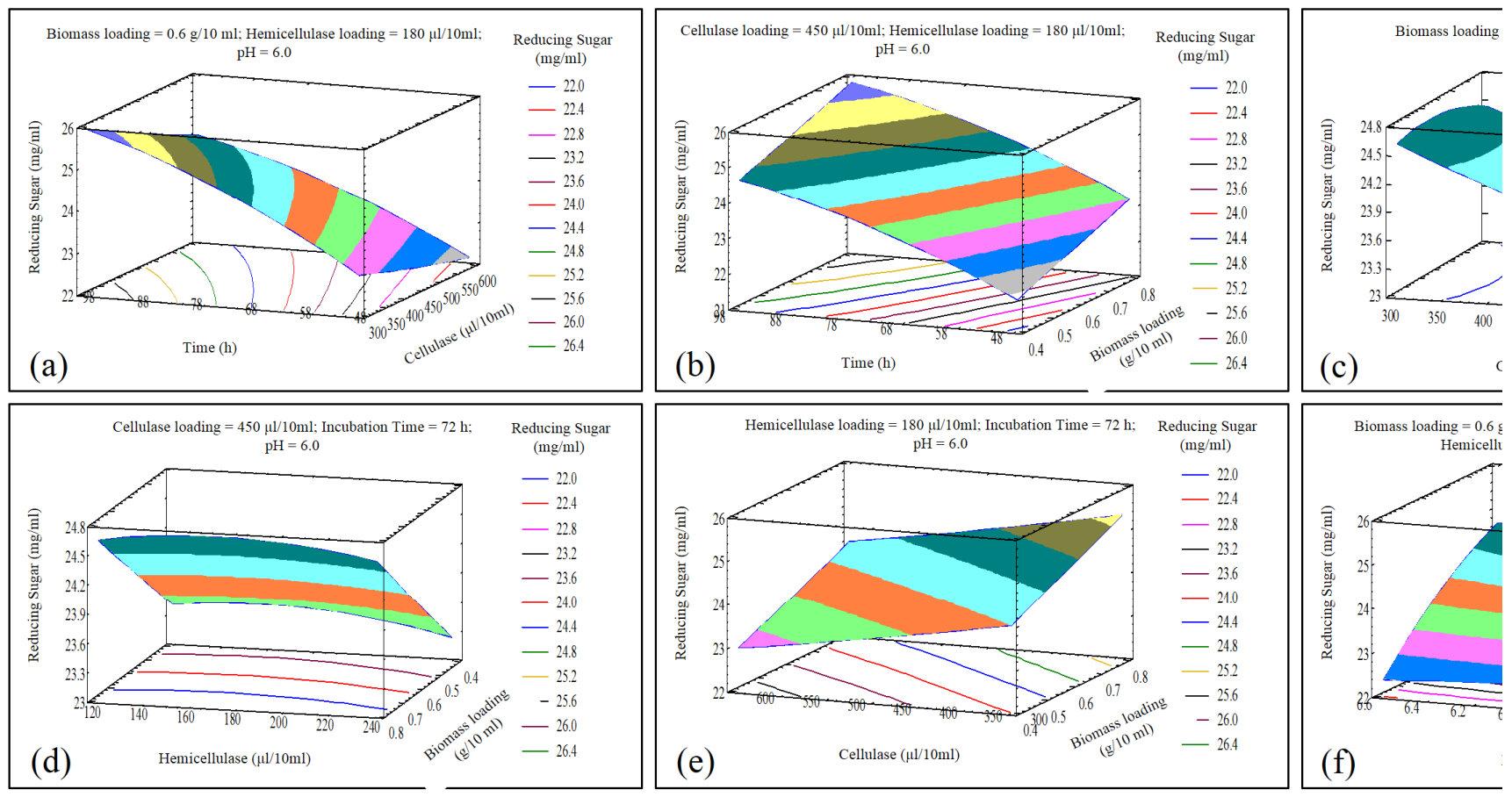

Fig 1. Response surface plots representing the effect of independent variables on reducing sugar yield (1a) the effect of cellulase and time on reducing sugar yield when the response surface is fixed at biomass loading $=0.6 \mathrm{~g} / 10 \mathrm{ml}$, hemicellulase $=180 \mu \mathrm{l} / 10 \mathrm{ml}$ and $\mathrm{pH}=6.0$; (1b) representing the effect of time and biomass loading on reducing sugar yield, when the response surface is fixed at cellulase loading $=450 \mu \mathrm{l} / 10 \mathrm{ml}$, hemicellulase $=180$ $\mu \mathrm{l} / 10 \mathrm{ml}, \mathrm{pH}=6.0$; (1c) representing the effect of cellulase and hemicellulase loading on reducing sugar yield, when the response surface is fixed at biomass loading $=0.6 \mathrm{~g} / 10 \mathrm{ml}$, time $=72 \mathrm{~h}, \mathrm{pH}=6.0 ;(1 \mathrm{~d})$ representing the effect of hemicellulase and biomass loading on reducing sugar yield, when the response surface is fixed at cellulase loading $=450 \mu 1 / 10 \mathrm{ml}$, time $=72 \mathrm{~h}, \mathrm{pH}=6.0$; (1e) representing the effect of biomass and cellulase loading on reducing sugar yield, when the response surface is fixed at hemicellulase loading $=180 \mu \mathrm{l} / 10$ $\mathrm{ml}$, time $=72 \mathrm{~h}$, and $\mathrm{pH}=6.0(1 \mathrm{f})$ representing the effect of incubation time and $\mathrm{pH}$ on reducing sugar yield, when the response surface is fixed at biomass loading $=0.6 \mathrm{~g} / 10 \mathrm{ml}$, hemicellulase loading $=180 \mu \mathrm{l} / 10 \mathrm{ml}$ and cellulase loading $=450 \mu \mathrm{l} / 10 \mathrm{ml}$. 


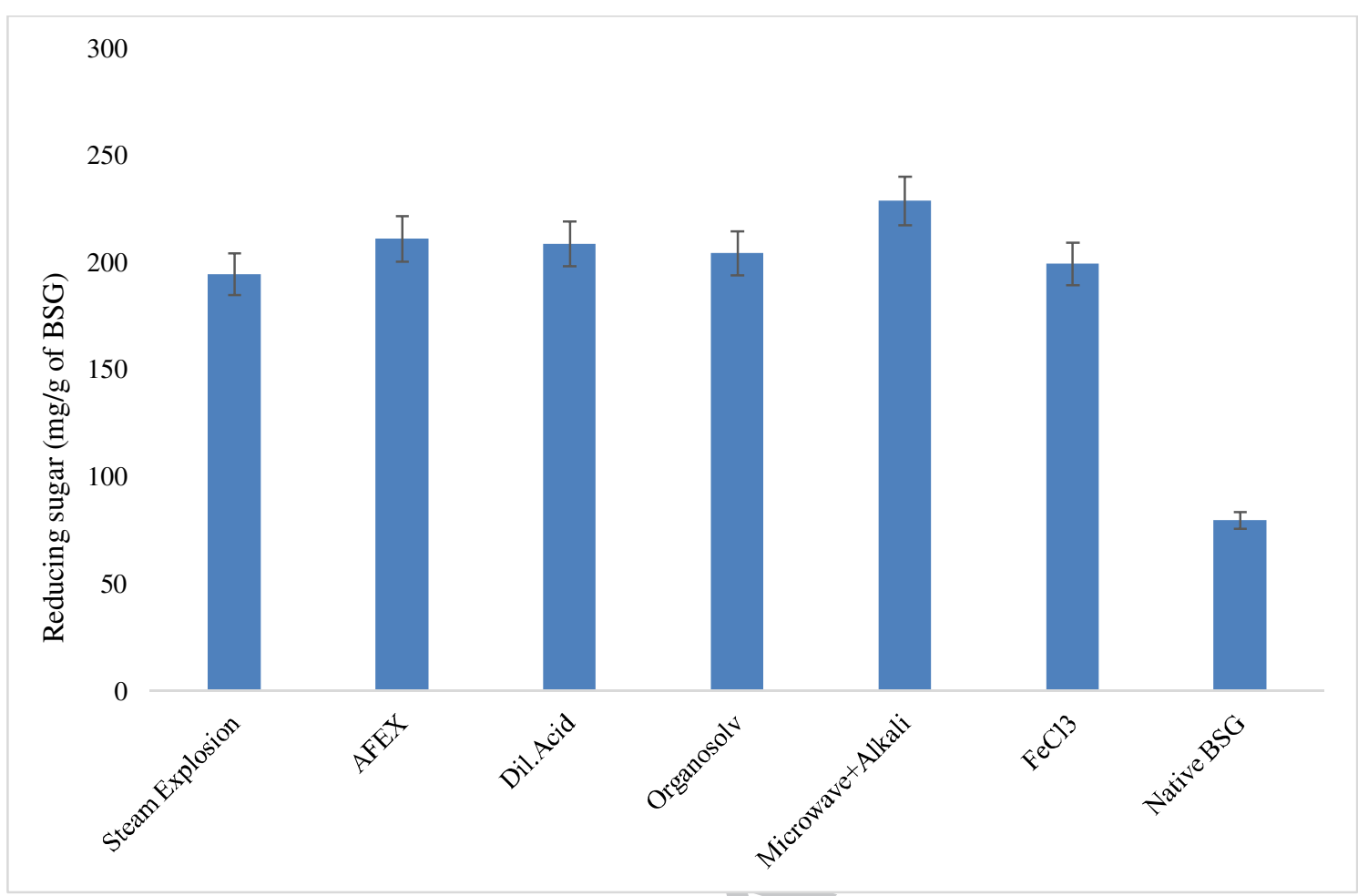

Fig 2. Total reducing sugar released (mg/g of BSG) after enzymatic hydrolysis of pretreated and native BSG 
Table 1. Process variables and level in CCD

\begin{tabular}{lcccccc}
\hline & Coded & \multicolumn{5}{c}{ Levels } \\
Independent variables & symbols & \multicolumn{5}{c}{} \\
\cline { 3 - 7 } & & -2 & -1 & 0 & +1 & +2 \\
\hline Biomass loading $(\mathrm{g} / 10 \mathrm{ml})$ & $X_{1}$ & 0.2 & 0.4 & 0.6 & 0.8 & 1 \\
Cellulase loading $(\mu \mathrm{l} / 10 \mathrm{ml})$ & $X_{2}$ & 150 & 300 & 450 & 600 & 750 \\
Hemicellulase loading $(\mu \mathrm{l} / 10 \mathrm{ml})$ & $X_{3}$ & 60 & 120 & 180 & 240 & 300 \\
$\mathrm{pH}$ & $X_{4}$ & 4.8 & 5.4 & 6.0 & 6.6 & 7.2 \\
Incubation time $(\mathrm{h})$ & $X_{5}$ & 24 & 48 & 72 & 96 & 120 \\
\hline
\end{tabular}


Table 2. CCD experimental designs for five independent variables, experimental and predicted values for total reducing sugar

\begin{tabular}{|c|c|c|c|c|c|c|c|}
\hline Run & $\begin{array}{c}\text { Biomass } \\
\text { loading } \\
(\mathrm{g} / 10 \mathrm{ml}) \\
X_{1}\end{array}$ & $\begin{array}{c}\text { Cellulase } \\
\text { loading } \\
(\mu \mathrm{l} / 10 \mathrm{ml}) \\
X_{2}\end{array}$ & $\begin{array}{c}\text { Hemicellulase } \\
\text { loading } \\
(\mu \mathrm{l} / 10 \mathrm{ml})\end{array}$ & $\begin{array}{c}X_{3} \\
\mathrm{pH}\end{array}$ & $\begin{array}{c}X_{4} \\
\text { Incubation } \\
\text { Time }(\mathrm{h}) \\
X_{5}\end{array}$ & $\begin{array}{c}\text { Experimental } \\
\text { total reducing } \\
\text { sugar } \\
(\mathrm{mg} / \mathrm{ml})\end{array}$ & $\begin{array}{c}\text { Predicted } \\
\text { total } \\
\text { reducing } \\
\text { sugar } \\
(\mathrm{mg} / \mathrm{ml})\end{array}$ \\
\hline 1 & 0.8 & 0.30 & 0.24 & 5.4 & 96 & 16.74 & 16.81 \\
\hline 2 & 0.8 & 0.30 & 0.24 & 6.6 & 48 & 13.27 & 13.34 \\
\hline 3 & 0.8 & 0.30 & 0.12 & 6.6 & 96 & 16.08 & 15.93 \\
\hline 4 & 0.6 & 0.15 & 0.18 & 6.0 & 72 & 15.21 & 15.30 \\
\hline 5 & 0.6 & 0.45 & 0.18 & 6.0 & 72 & 14.14 & 14.10 \\
\hline 6 & 0.6 & 0.45 & 0.18 & 6.0 & 72 & 14.14 & 14.10 \\
\hline 7 & 0.8 & 0.30 & 0.12 & 5.4 & 48 & 13.84 & 13.69 \\
\hline 8 & 0.6 & 0.75 & 0.18 & 6.0 & 72 & 13.09 & 13.18 \\
\hline 9 & 0.8 & 0.60 & 0.24 & 6.6 & 96 & 14.44 & 14.51 \\
\hline 10 & 0.8 & 0.60 & 0.12 & 6.6 & 48 & 12.73 & 12.58 \\
\hline 11 & 0.6 & 0.45 & 0.60 & 6.0 & 72 & 13.19 & 13.72 \\
\hline 12 & 0.8 & 0.60 & 0.12 & 5.4 & 96 & 15.64 & 15.49 \\
\hline 13 & 0.4 & 0.60 & 0.24 & 5.4 & 96 & 14.14 & 14.20 \\
\hline 14 & 0.4 & 0.60 & 0.12 & 5.4 & 48 & 11.73 & 11.58 \\
\hline 15 & 0.6 & 0.45 & 0.18 & 6.0 & 24 & 10.40 & 10.49 \\
\hline 16 & 0.6 & 0.45 & 0.18 & 4.8 & 72 & 14.48 & 14.57 \\
\hline 17 & 0.6 & 0.45 & 0.18 & 6.0 & 120 & 15.69 & 15.78 \\
\hline 18 & 0.6 & 0.45 & 0.18 & 6.0 & 72 & 14.14 & 14.10 \\
\hline 19 & 0.4 & 0.60 & 0.12 & 6.6 & 96 & 13.56 & 13.41 \\
\hline 20 & 0.4 & 0.30 & 0.12 & 6.6 & 48 & 12.25 & 12.10 \\
\hline 21 & 0.6 & 0.45 & 0.18 & 6.0 & 72 & 14.14 & 14.10 \\
\hline 22 & 0.2 & 0.45 & 0.18 & 6.0 & 72 & 12.76 & 12.85 \\
\hline 23 & 0.6 & 0.45 & 0.30 & 6.0 & 72 & 13.81 & 13.46 \\
\hline 24 & 0.4 & 0.30 & 0.12 & 5.4 & 96 & 15.85 & 15.70 \\
\hline 25 & 0.6 & 0.45 & 0.18 & 7.2 & 72 & 13.28 & 13.37 \\
\hline 26 & 1.0 & 0.45 & 0.18 & 6.0 & 72 & 15.33 & 15.42 \\
\hline 27 & 0.4 & 0.30 & 0.24 & 6.6 & 96 & 14.42 & 14.49 \\
\hline 28 & 0.4 & 0.30 & 0.24 & 5.4 & 48 & 12.08 & 12.14 \\
\hline 29 & 0.4 & 0.60 & 0.24 & 6.6 & 48 & 11.13 & 11.20 \\
\hline 30 & 0.8 & 0.60 & 0.24 & 5.4 & 48 & 12.68 & 12.75 \\
\hline & & & & & & & \\
\hline 12 & & & & & & \\
\hline
\end{tabular}


Table 3. Compositional analysis of untreated and pretreated samples of BSG

\begin{tabular}{|c|c|c|c|c|c|c|c|}
\hline Pretreatment & $\begin{array}{l}\text { Cellulose } \\
\text { (glucose) }\end{array}$ & Galactan & Arabinan & Xylan & Mannan & AIL & ASL \\
\hline AFEX & $21.32 \pm 0.9^{\mathrm{a}}$ & $0.40 \pm 0.3^{\mathrm{a}}$ & $2.91 \pm 0.4^{\mathrm{a}}$ & $11.23 \pm 0.3^{\mathrm{a}}$ & $0.30 \pm 0.1^{\mathrm{a}}$ & $21.10 \pm 0.1^{\mathrm{a}}$ & $7.26 \pm 0.4^{\mathrm{a}}$ \\
\hline $\begin{array}{l}\text { Steam } \\
\text { Explosion }\end{array}$ & $19.31 \pm 0.45^{\mathrm{b}}$ & $0.83 \pm 0.12^{\mathrm{b}}$ & $6.57 \pm 0.3^{b}$ & $15.41 \pm 0.7^{\mathrm{b}}$ & $0.43 \pm 0.5^{\mathrm{b}}$ & $21.87 \pm 0.7^{\mathrm{a}}$ & $7.01 \pm 0.6^{\mathrm{a}}$ \\
\hline $\begin{array}{l}\text { Dil. Acid } \\
\text { hydrolysis }\end{array}$ & $35.43 \pm 1.1^{\mathrm{c}}$ & $0.35 \pm 0.9^{c}$ & $2.54 \pm 0.75^{\mathrm{c}}$ & $13.52 \pm 0.4^{\mathrm{c}}$ & $0.21 \pm 0.3^{c}$ & $21.76 \pm 0.4^{\mathrm{a}}$ & $4.42 \pm 0.9^{b}$ \\
\hline $\begin{array}{l}\text { Ferric } \\
\text { Chloride }\end{array}$ & $17.99 \pm 0.7^{b}$ & $0.45 \pm 0.4^{\mathrm{d}}$ & $5.28 \pm 0.8^{\mathrm{d}}$ & $3.61 \pm 0.9^{\mathrm{d}}$ & $0.21 \pm 0.2^{c}$ & $20.61 \pm 0.5^{a b}$ & $5.69 \pm 0.21^{\mathrm{c}}$ \\
\hline Organosolv & $26.42 \pm 0.4^{\mathrm{d}}$ & $0.39 \pm 0.1^{\mathrm{ac}}$ & $2.96 \pm 0.15^{\mathrm{a}}$ & $6.45 \pm 0.4^{\mathrm{e}}$ & & $11.68 \pm 1.4^{\mathrm{c}}$ & $5.89 \pm 0.43^{\mathrm{c}}$ \\
\hline $\begin{array}{l}\text { Microwave- } \\
\text { alkali }\end{array}$ & $43.67 \pm 1.2^{\mathrm{e}}$ & $0.70 \pm 0.6^{\mathrm{e}}$ & $5.35 \pm 0.2^{\mathrm{d}}$ & $11.53 \pm 0.2^{\mathrm{a}}$ & $0.46 \pm 0.54^{\mathrm{e}}$ & $9.09 \pm 0.65^{\mathrm{d}}$ & $2.77 \pm 0.9^{\mathrm{d}}$ \\
\hline Native BSG & $19.21 \pm 1.3^{\mathrm{b}}$ & $1.06 \pm 0.4^{\mathrm{f}}$ & $7.99 \pm 0.9^{\mathrm{e}}$ & $17.21 \pm 0.7^{\mathrm{f}}$ & $0.68 \pm 0.1^{\mathrm{f}}$ & $23.36 \pm 1.2^{\mathrm{b}}$ & $7.12 \pm 0.4^{\mathrm{a}}$ \\
\hline
\end{tabular}




\section{Highlights}

- Brewer's spent grain was subjected to six different pretreatment and compared.

- Extensive delignification was achieved with all the pretreatments but in different extent.

- Enzymatic hydrolysis was optimised using RSM to obtain maximum reducing sugar yield.

- Microwave assisted alkali pretreatment leads to high reducing sugar yield and delignification.

- Microwave assisted alkali pretreated BSG yielded $228.25 \mathrm{mg}$ of reducing sugar/g of BSG. 